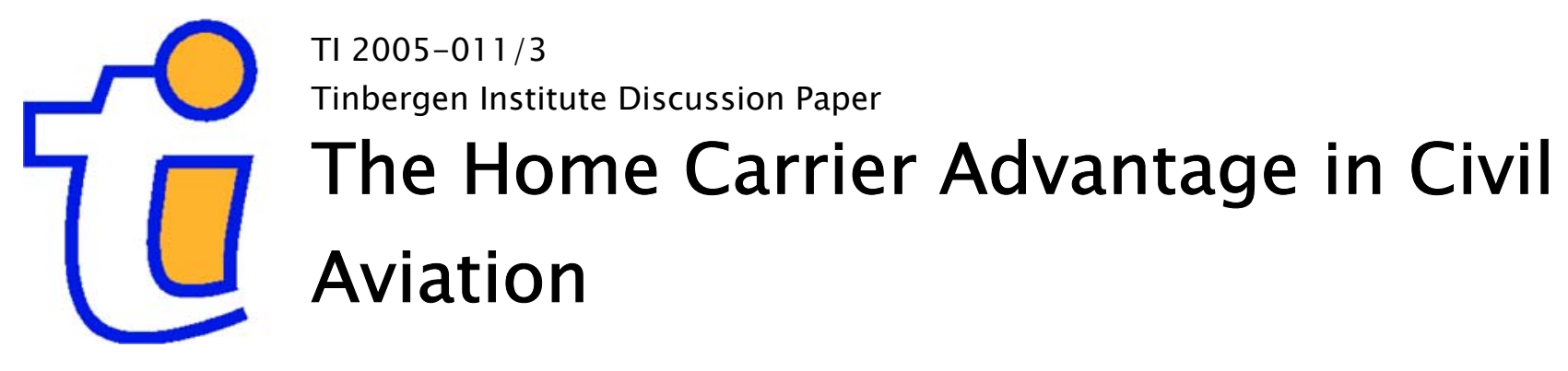

Mark Lijesen ${ }^{1}$

Peter Nijkamp2,3

Eric Pels²

Piet Rietveld2,3

${ }^{\prime}$ Netherlands Bureau for Economic Policy (CPB),

2 Faculty of Economics and Business Administration, Vrije Universiteit Amsterdam,

3 Tinbergen Institute. 
Tinbergen Institute

The Tinbergen Institute is the institute for economic research of the Erasmus Universiteit Rotterdam, Universiteit van Amsterdam, and Vrije Universiteit Amsterdam.

Tinbergen Institute Amsterdam

Roetersstraat 31

1018 WB Amsterdam

The Netherlands

Tel.: $\quad+31(0) 205513500$

Fax: $\quad+31(0) 205513555$

Tinbergen Institute Rotterdam

Burg. Oudlaan 50

3062 PA Amsterdam

The Netherlands

Tel.: $\quad+31(0) 104088900$

Fax: $\quad+31(0) 104089031$

Please send questions and/or remarks of nonscientific nature to driessen@tinbergen.nl.

Most TI discussion papers can be downloaded at http://www.tinbergen.nl. 


\title{
The Home Carrier Advantage in Civil Aviation
}

Mark Lijesen ${ }^{1}$, Peter Nijkamp ${ }^{2}$, Eric Pels ${ }^{2}$ and Piet Rietveld ${ }^{2}$

\begin{abstract}
This paper analyzes the relative economic power position of home carriers in hub-and-spoke systems. Hub-andspoke systems may lower costs on densely traveled routes and enable economically viable operations on less densely traveled routes. The reverse side is probably that carriers enjoy significant market power at their home base, often labeled the home carrier advantage. The paper offers a concise overview of the literature in this field, and addresses next empirically this issue for European home carriers. We found empirically that at least some European carriers charge premiums for flights originating from their hubs. The hub premiums of Lufthansa, Swissair and Air France are significantly higher than those of the other companies in our sample.
\end{abstract}

\section{Introduction}

Air transportation is a transport mode that is already more than one century old. It started off as an adventurous activity of a few pioneers, but soon turned into a commercial activity oriented toward the physical transport of both people and goods. Its strategic-military value was also soon recognized, in particular during the World War I. Land and airspace became national territories with a strong involvement of governments. The Chicago Convention was a clear sign of the complexity of treating the airspace both as a closed area for national competence and as an open area for transborder transport.

The national perspective on airspace also favored the emergence of national airlines, as they were enabled to start up in the protected and non-competitive area of individual nations. Airlines became the symbol of national feelings and pride, comparable to the national flag or the national hymn. Efficiency motives were overruled by national interests. In the period after World War II, the protected aviation market led to a patchwork of rather disconnected network segments dominated by home carriers (national flag carriers) representing national interests and feelings. Its development was hampered by an overwhelming amount of institutional barriers which made air transport a relatively expensive and inefficiently operated transport mode.

A real breakthrough - with a rapidly increasing geographical mobility - took place as a result of the deregulation movement which started in North America, but which also reached other regions where national interests historically played a prominent place (e.g., Europe) in less than a decade (see Berechman and Shy 1998).

The deregulation movement has exerted an unprecedented impact on the operation, logistics and market organization of airlines, as unnecessary restrictions on airfares, freedom of entry and exit, route structures, airport development and flight frequencies were abolished. Consequently, competition became a driving force in the dynamics of the airline industry,

\footnotetext{
${ }^{1}$ Netherlands Bureau for Economic Policy Analysis (CPB), The Hague
} 
where network constellations (route structures, hub-and-spoke systems) acted as critical parameters for economizing on airfares in the competitive multi-actor transport market (see Brueckner and Zhang 2001, Pels et al. 1997). Another critical parameter for competitive pricing turned out to be service-quality competition (see Morrison and Winston 1995). Those issues will be addressed in this paper from the perspective of domestic (home) carriers.

We have outlined above that the importance of civil aviation to modern society is quite significant. This sector is not only a large and rapidly growing industry by itself, it also fuels several other important industries directly (e.g. tourism) or indirectly, through increased travel possibilities.

We will start here with a concise sketch of recent developments in Europe. The airline industry itself has seen rapid growth over the past three decades. The number of passenger kilometers in EU-15 countries rose from 33 billion in 1970 to 281 billion in 2000, an average annual growth of 7.4 percent. In the same period, major institutional and regulatory changes have occurred. Civil aviation has for long been a heavily regulated sector, mainly because of the strategic importance of air transport. The era of regulation ended in 1978, when US Congress adopted the Airline Deregulation Act. In the same year, the US and the Netherlands signed a very liberal bilateral agreement on 'open skies', inducing an increase in competition in Trans-Atlantic markets.

Europe's airline industry was by then still heavily regulated, often with domestic monopolies for the national flag carrier and duopolies of two flag carriers on international routes. Passengers had the choice between the home carrier of the country of origin and the home carrier of the country of destination. In 1984, The UK and The Netherlands signed a new bilateral agreement that effectively deregulated the air services between these countries. It was the first serious step towards the deregulation of the European airspace, which neared completion in 1992, in time to serve the now integrated European market.

Like in the US in 1978, the 1992 deregulation fuelled the emergence of hub-and-spoke systems in Europe. Together with the entry of former charter airlines and the new low cost carriers into the deregulated market, the hub-and-spoke system increased competitive pressure. Besides the home carrier of the country of origin and the home carrier of the country of destination, passengers can now choose from several other carriers serving the route through their hub.

This paper focuses on the relative position of the home carriers in hub-and-spoke systems. We will however not deal with the subject in isolation, but rather give a somewhat broader review of important themes in civil aviation. To an economist, civil aviation offers a rich variety of research subjects, such as market failure, in the form of external costs, the network structure of the industry and its successive deregulation (in both the US and Europe). The next section will briefly touch upon some prominent research subjects present in the current stream

\footnotetext{
${ }^{2}$ Free University, Amsterdam
} 
of economic literature on civil aviation. ${ }^{3}$ Section 3 will dive deeper into the hub-and-spoke system, which acts as a central theme in aviation economics. We will introduce the phenomenon of the home carrier advantage in section 4 followed by an empirical analysis on the subject. Section 6 offers concluding remarks and discusses policy implications.

\section{Important Issues in Modern Aviation Economics}

In this section we will briefly address three major economic issues; externalities in the airline industry, regulatory systems and the network ramification of modern airlines

\subsection{External costs}

External costs of a good are the costs that a person imposes on others by consuming the good. Schipper et al. (2003) mention emissions of pollutants, aircraft noise and accidents as external costs of air transport. Wit et al. (2003) provide a somewhat more extensive list. They distinguish between several types of emissions by their effects (climate change, ozone layer depletion, local air quality effects and oder nuisance). They also mention aircraft noise (nuisance and health impacts, as well as indirect land use impacts) and accidents (direct risks and indirect land use impacts), Furthermore, Wit et al. (2003) mention water and soil pollution, congestion of runways and air space, land use impacts of airports and impacts on nature conservation (e.g. loss of tranquillity). Whether congestion of runways and air space are considered external is merely a matter of aggregation. It depends on whether one looks at the level of the individual traveler or the entire industry.

Borenstein and Zimmerman (1988) analyze the effect of airplane accidents on carrier demand. They find a negative effect, as was to be expected. However, they also conclude that most of the effect is gone after two months. Rose (1992) explains this short period by the relatively small serial correlation of accidents with the same carrier, implying that an airline's safety record hardly informs travelers on accident probability.

From a welfare-theoretic and policy perspective, the presence of externalities is important due to its implications for taxation schemes for airlines, for airport development plans and for regulatory frameworks for the airline sector. Inclusion of externalities in airline cost schemes and regulations should avoid privileges for home carriers in a certain country or at a given airport.

\subsection{Deregulation}

As mentioned earlier, the airline industry is historically regarded as a strategically important sector for any nation. The ensuing regulation of this sector has caused large economic inefficiencies. The deregulation of civil aviation in the United States in 1978 and

\footnotetext{
${ }^{3}$ For an extensive overview of recent literature, see Nijkamp and Button (2003).
} 
the early nineties in Europe induced great changes in the airline industry (see Doganis, 1991) for an overview). Following these changes, a vast volume of literature emerged. Winston (1993) provides an extensive overview on publications on deregulation in the US, Marín (1995) is an example of the relatively small amount of European studies. Specific topics related to deregulation are contestability (Baker and Pratt, 1989 and Button, 1996), yield management strategies and airline productivity.

Since the implementation of deregulation, airlines engage in dynamic price discrimination to maximize total revenues once flight schedules are set. This phenomenon is known as yield management. Reece and Sobel (2000) link yield management to price discrimination under capacity constraints. One of the issues here is how to distinguish between passengers based on their willingness to pay for a flight. The main mechanism for this distinction is to differentiate fares by the amount of time they are booked ahead of departure. The subject has attracted the attention from economists, both from an operations research viewpoint (e.g. Dana, 1999; see McGill and Van Ryzin (1999) for an extensive review) and from a perspective of economic efficiency (Botimer, 1996).

Efficiency is also the main concern of another stream of recent literature, albeit from a different viewpoint. Productive efficiency is the main theme of a stream of literature devoted to productivity analysis. Oum and Yu (1998) perform a broad and comprehensive assessment of carrier productivity. Marín (1998) focuses on productivity differences between European carriers, whereas Ahn et al. (1999) compare Asian and North-American carriers.

The issue of deregulation has prompted economists to study the airline sector also from the perspective of industrial organization, and this has in the past led to interesting and novel analytical frameworks for investigating regulatory systems' impact on the aviation sector.

\subsection{Aviation as a network industry}

Aviation is commonly known as a network industry. The lines in the network are neither visible nor physical, but create nevertheless a connectivity infrastructure. Aviation is a nodal network, the nodes in the network being the airports. Network economics has become a new angle for studying the airline industry.

Economic literature on airports traditionally focussed on financing and investment decisions. Contemporary airport economics cover a much wider range of subjects, such as privatization and liberalization, pricing strategies and performance measurement (Doganis, 1996). Furthermore, the concept of airport choice and valuation of airport attributes has gained increasing interest, both from the point of view of the traveler (e.g. Pels et al., 2002) and the point of view of the airline (Berechman and De Wit, 1996).

Aviation networks require an efficient operation and management because of their capacity limits. The increase in air traffic has created the problem of airport congestion. Economists almost instinctively propose to battle congestion by prices, explaining why 
congestion pricing is such a well-covered topic in economic literature. Recent advances in airport congestion pricing may be found in Daniel and Pahwa (2000), Brueckner (2002) and Pels and Verhoef (2004). The latter contribution shows that airport congestion pricing need not be optimal when airlines have significant market power.

The network structure also impacts on the cost structure of the industry. Networks are often characterized by economies of density, implying that higher densities, e.g. more passengers per flight leg, bring down unit costs. Economies of density are a special case of scale economies. The main difference is that economies of density relate to an increase of output at a given geographical scale, whereas economies of scale relate to an increase of output in general (Oum and Waters, 1996).

Economies of density have two important implications for the airline industry, each of them representing a way to utilize economies of density. The first implication is the formation of hub-and-spoke networks, which will be discussed more extensively in the next section. The second implication regards code-sharing and alliances between airlines.

Park (1997) distinguishes between two types of alliances. The first type is the complementary alliance, in which the networks of the two carriers complement each other. The second type is the parallel alliance, where two competitors join their networks. Park shows that complementary networks increase welfare, whereas parallel networks decrease welfare. Bissessur and Alamdari (1998) also mention network complementarity as an important factor affecting the operational success of alliances. Brueckner and Pels (2004) show that the consolidation of the (largely parallel) Northwest-KLM and Sky Team alliances, following the merger between KLM and Air France, has anti-competitive effects, decreasing overall welfare.

It is thus clear that network constellation and usage, as well as network policies (on the side of both airlines and airports) have wide-ranging implications for the development of this sector, including issues like point-to-point flight schedules, the size of new generations of aircraft and the role of the public sector.

\section{The Hub-and-Spoke System}

The abolishment of regulation and the entry of new competitors forced existing airlines to rethink their operations and urged them to exploit economies of density. The hub-and spoke system enabled carriers to concentrate passengers on flight legs, thus inducing lower costs per passenger through the exploitation of density economies. The hub-and-spoke system rapidly developed in the US as a consequence of the 1978 liberalization. Somewhat similar systems had been in use in Europe. Although similar in appearance, the 'old' European hub-and-spoke systems were different from those in the US and from those presently evolving in Europe. Europe's tradition of national carriers, each concentrating its operations at one or more national airports, created a system of star-shaped networks without emphasis on connecting 
flights. The latter is a central feature in the present hub-and-spoke system, as we will see further on.

The advantage of a hub-and-spoke system may be best described by sketching a simple airline network with four nodes. Figure 1 depicts two ways of connecting all nodes together. The figure on the left hand side represents a fully connected network in which all nodes are connected through point-to-point relations. The figure on the right hand side is a hub-andspoke network. Airport $\mathrm{H}$ is the hub airport through which all other airports are connected. ${ }^{4}$

Figure 1 A fully-connected network versus a hub-and-spoke network
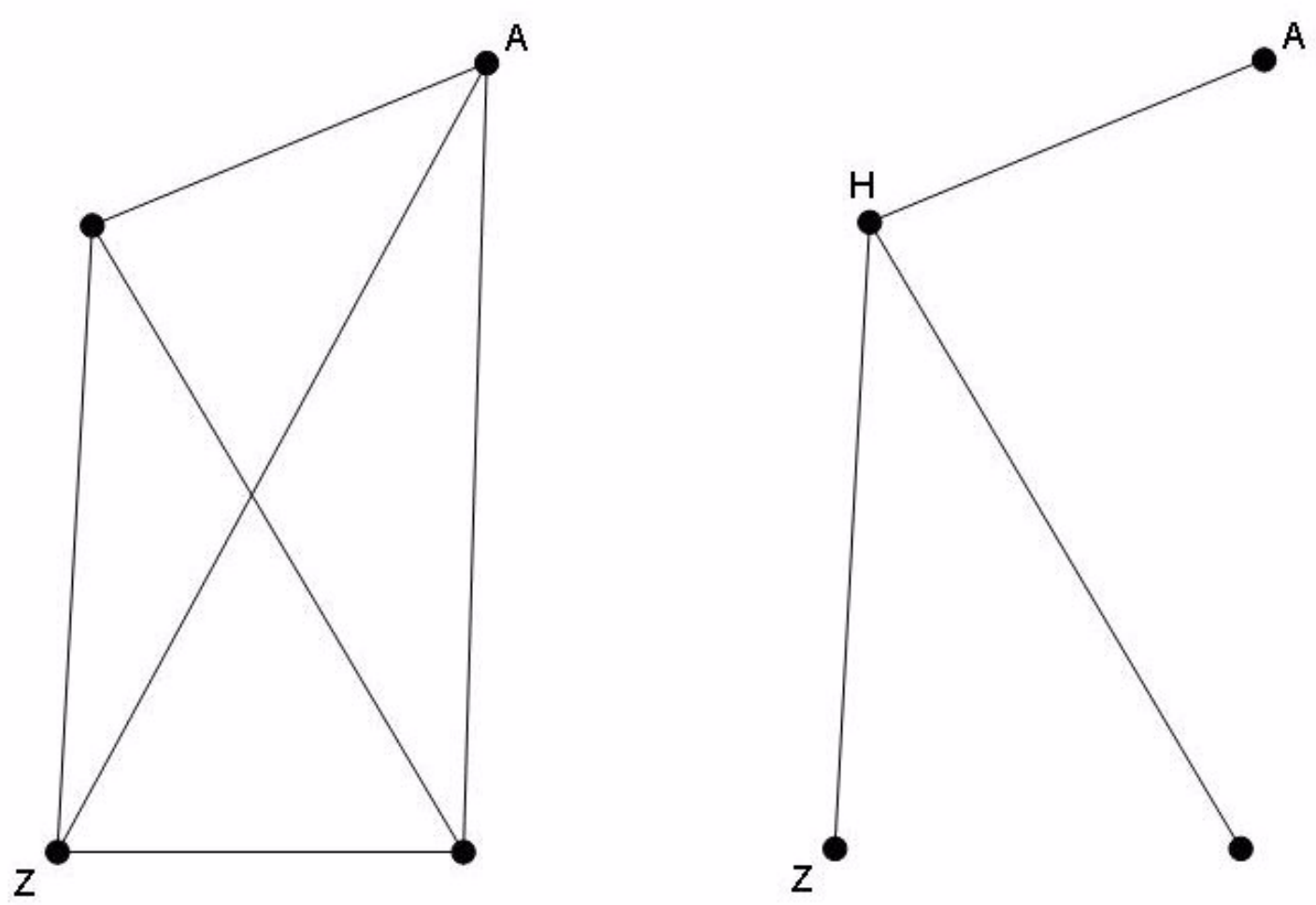

It is clear from the figure that it takes only three routes to connect all the nodes in the huband-spoke network, whereas it takes six routes in the fully connected network. Based on this simple example, one can easily imagine why the hub-and-spoke system can be a much more efficient way to connect all the nodes. Whether a hub-and-spoke network is more efficient depends on the number of nodes in the network and the density of travel demand on each nodal pair. Both effects may be illustrated using Figure 1. Suppose we added an extra node to both networks. This would require four extra routes in the fully-connected network, and only one in the hub-and-spoke network, increasing the relative efficiency of the hub-and-spoke network. The effect of the density of travel demand may be illustrated by assuming that nodal 
pair A-Z has very high travel demand. In this case it would not be efficient to connect $A$ and $\mathrm{Z}$ through hub $\mathrm{H}$, as the economies of density are already exhausted and the extra connection imposes costs on the airline as well as its travelers.

Table $1 \quad$ Market shares (\% of departing passengers) of home carrier on main hubs in the US and Europe, January 2003

\begin{tabular}{|c|c|c|c|}
\hline \multirow[t]{2}{*}{ Hub airport } & \multirow[t]{2}{*}{ Home carrier } & \multicolumn{2}{|c|}{ Market share } \\
\hline & & European data & US-DOT data \\
\hline \multicolumn{4}{|l|}{$U S$} \\
\hline Atlanta & Delta & & $70 \%$ \\
\hline \multirow[t]{2}{*}{ Chicago O'Hare } & United & & $42 \%$ \\
\hline & American & & $28 \%$ \\
\hline Dallas Fort Worth & American & & $61 \%$ \\
\hline Denver & United & & $53 \%$ \\
\hline Miami & American & & $54 \%$ \\
\hline Houston Intercontinental & Continental & & $70 \%$ \\
\hline Minneapolis St Paul & NorthWest & & $70 \%$ \\
\hline Detroit & NorthWest & & $66 \%$ \\
\hline Newark & Continental & & $51 \%$ \\
\hline San Francisco & United & & $48 \%$ \\
\hline \multicolumn{4}{|l|}{ Europe } \\
\hline London Heathrow & British Airways & $45 \%$ & $45 \%$ \\
\hline Paris CDG & Air France & $57 \%$ & $74 \%$ \\
\hline Frankfurt & Lufthansa & $60 \%$ & $73 \%$ \\
\hline Amsterdam & KLM & $48 \%$ & $81 \%$ \\
\hline Milan Malpensa & Alitalia & NA & $66 \%$ \\
\hline
\end{tabular}

Sources: DOT, T100 market database, European airlines and airports websites

If an airline centers its operations at a hub airport, the airline is likely to be an important airline at that airport. Table 1 lists the market shares of home carriers on their hubs. For the European hubs, we distinguish between US Department of Transport-data and European data. The former reflect market shares on combined routes from the listed European airports to destinations in the US (e.g., British Airways and its code-sharing partners carry 45 percent of all passengers from London Heathrow to US destinations). European data relate to the market share of all flights leaving from the hub, but come from different sources, which may cause some inconsistencies. For instance, in the cases of KLM and Air France airline data relate to calendar year 2003, whereas airport data relate to the fiscal year 2003/2004. The impact of

\footnotetext{
${ }^{4}$ For a more extensive discussion on hub-and-spoke operations, see Chapter 5 in Hanlon (1999).
} 
these inconsistencies on the general image is probably minor. The difference between US data and European data is especially large for KLM.

An airport is always almost used as a hub by a single airline, the only exception being Chicago O'Hare, acting as a hub for both American Airlines and United Airlines. We refer to the hub-based airline as the home carrier, expressing that the carrier is at home at its hub airport. In a city pair-market, we define the home carrier as the carrier whose hub is either the origin airport or the destination airport. The special position of the home carrier makes one wonder whether it has an advantage competing for passengers, following from the nature of its hub-and-spoke operations, and how to interpret this advantage.

To understand the aspects of the possible advantage of the home carrier, we need to place the position of the home carrier in a wider perspective. First, we need to acknowledge that carriers compete for travelers on city pair markets. As far as a traveler is concerned, the product he buys is getting from his origin to his destination. The traveler makes a combined choice of carrier and itinerary, depending on the availability of combinations. If a traveler were to fly from Amsterdam to Florence, for instance, he may choose between a direct KLM flight and an Air France flight via Paris. As Air France does not offer direct flights from Amsterdam to Florence, carrier choice and itinerary choice are connected.

Each trip alternative that takes the passenger from his origin to his destination is judged on its trip characteristics as well as on the characteristics of the carrier operating the flights. Figure 2 depicts a stylized version of the process of itinerary and carrier choice.

Figure 2 The process of itinerary and carrier choice

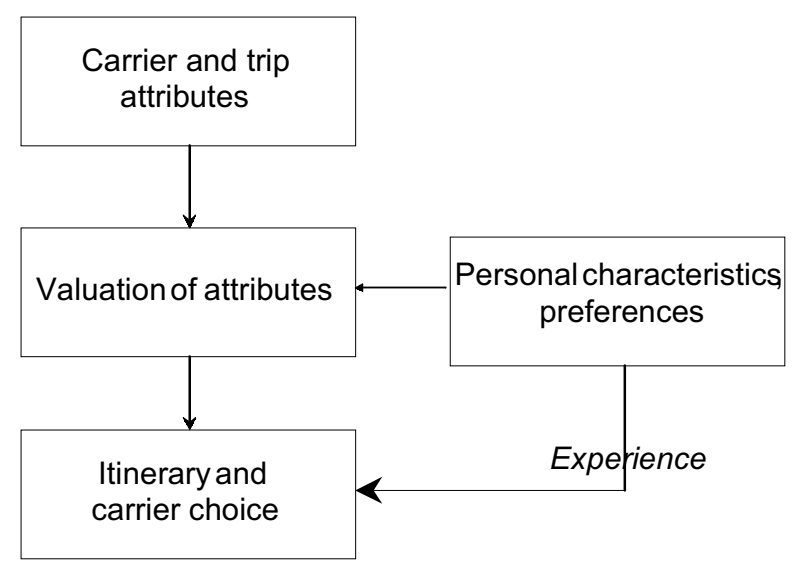

Each traveler takes into account the attributes (e.g., frequency, in-flight time, transfer time, access time) of all possible combinations of carriers and itineraries on the city pair he plans to travel. The traveler values each of the attributes before making his choice. The traveler's valuation depends on his personal characteristics, such as age, gender, trip purpose, 
income and experience. After making the choice, the traveler completes the trip, thus gaining new experience, which may alter his valuation of some of the attributes.

Present debates relate to the question whether the hub-and-spoke system will remain the dominant organization principle in the airline industry. Airfares and inconvenience for the traveler have to be traded-off against each other. Especially in the emerging open European skies it is questionable whether a few dominant hubs will arise, given the national interests of individual nations and the relatively small distances in Europe. National flag carriers have lost their dominant position, but the system of home carriers is a very prominent feature of European aviation.

\section{Advantages of Home Carriers}

In the previous section we argued that the home carrier may have an advantage over its competitors because of favorable flight characteristics. Apart from flight characteristics, other factors may play a role as well, like grandfathering rights in airport slot allocation, familiarity with the local situation and good relations with the home airport. In the remainder of this section, we will focus on flight-related advantages however. To assess the relative position of the home carrier it is important to know which trip and carrier characteristics differ between the home carrier and the other carriers. We distinguish between five main characteristics:

- route

- frequency

- fare

- frequent flier programs

- other attributes

We will now briefly discuss each of these five items.

\section{Route}

The obvious advantage of a home carrier over its competitors is that it generally offers direct flights, whereas its competitors (other than the destination's home carrier) offer indirect flights. Direct flights have two advantages over indirect flights. First, travel time is shorter. In-vehicle time is shorter because the overall distance on a direct flight is shorter. Fridström and Thune-Larsen $(1989)$ and Bhat $(1995,1997)$ find that in-vehicle travel time influences travel choices. Furthermore, total travel time will be shorter, as the transfer itself takes time as well.

The second advantage is that the transfer may be experienced as a negative characteristic, because of the discomfort of having to find your way at an unknown airport and risks like losing luggage and missing connecting flights. Kanafani and Ghobrial (1985) find a strong route choice effect for non-direct flights. Ghobrial (1993) also finds a negative effect of 
intermediate stops. Harvey (1987) finds that connecting flights are poor alternatives for direct flights, but finds no difference between non-stop and multi-stop flights without a transfer. This suggests that the change of plane aspect of non-direct flights weighs heavier than the extra travel time involved and the possible discomfort of an extra landing and take off. Clearly, route advantages are a key element in home carrier policy.

\section{Frequency}

A carrier is more likely to offer a high frequency from its home airport than carriers operating a hub elsewhere. Chances of departing or arriving at a desired time are positively related to flight frequencies. Therefore, frequency is often used as a proxy for schedule convenience (Ghobrial, 1993, Kanafani and Ghobrial, 1985, Bath, 1995, Proussaloglou and Koppelman, 1995, Suzuki 2000). Frequency is one of the quality aspects of modern airlines and therefore plays an important role in consumer choices.

\section{Cost advantages}

The hub-and-spoke system is based on economies of density. It allows carriers to collect passengers at all nodes and concentrate them in the hub. This enables the carrier to use larger planes and reach a higher load factor on them, thus decreasing the costs per passenger. Lower fares for longer flights are actually observed in practice. On the other hand, costs are also raised somewhat by the hub-and-spoke system, because indirect flights span longer distances and require extra landings and take-offs. Berry, Carnall and Spiller (1996) find empirical evidence for the cost-reducing effect of the hub-and-spoke system. Brueckner, Dyer and Spiller (1992) as well as Brueckner and Spiller (1994) focus on economies of density as an explanation for differences in fares.

Being the home carrier also gives a carrier some market power, allowing it to raise fares above cost levels. Brueckner, Dyer and Spiller (1992) find that hub-originating and hubterminating passengers pay higher fares, but cost advantages due to economies of density are passed on to passengers, thus reducing fares overall. The issue of fares in hub airports will be discussed in more detail below.

\section{Frequent flyer programs}

Frequent flyer programs (FFPs) are a well known marketing device in civil aviation worldwide and may be viewed as a carrier characteristic. Customers acquire credit points from a specific carrier in relation to distance traveled. These points can then be used for gifts, free travel or for upgrades (i.e., to have an economy class ticket upgraded to a business class ticket).

FFP's favor the home carrier because of their non-linearity: the awards grow as points accumulate. This feature causes increasing marginal returns, thus rewarding loyalty, 
especially so for the home carrier. After all, the home carrier is the carrier that flies most routes from the traveler's home town, thereby offering the largest opportunities to both collect and use points. The latter is confirmed by $\mathrm{Toh}$ and $\mathrm{Hu}$ (1988), who name frequent flier programs as a factor affecting carrier choice. They state that small airlines with limited networks have a disadvantage in this respect. FFP's may essentially be seen as a fringe benefit of the airline sector for frequent travelers.

\section{Other attributes}

Other trip and carrier characteristics are generally not related to the home airport of the carrier, although some aspects may play a role. Language may influence carrier choice, especially in countries where citizens have little education in other languages than their mother tongue. (Swait and Bernardino, 2000). For some consumers, flying with a carrier from their own nationality may be a favorable characteristic as well, either in the form of national pride or feeling at home. ${ }^{5}$

Furthermore, if cultural taste variations (for instance, with respect to food or leg space) are large, the home carrier will find it easier to adjust to local preferences. Swait and Bernardino (2000) find that, on three routes from different origins, there are some taste differences regarding food, in-flight entertainment and the design of the frequent flyer program.

A final point to be mentioned is that a home carrier may encounter economies of density in marketing in its home region, as a general marketing campaign can be expected to have an effect on all routes offered from the home airport.

\section{Consequences of home carrier advantages for fares.}

Existing studies analyzing features of the hub-and-spoke system mainly focus on the situation in the US. The focus of our analysis is on European civil aviation, more specific on Europe's large traditional carriers. Relatively new carriers like Ryanair and easyJet, however successful some of them may be, are not taken into account in our analysis, as they do not adopt the hub-and-spoke system. The European focus is an important contribution to earlier work. Almost all studies relating to the home carrier advantage have a US background. Europe's airline industry has a different structure than that in the US, as it evolved from a history of national carriers. The networks that these carriers operate sometimes still bear the signs of Europe's history, especially with regard to connecting former colonies to their homeland.

The saying that time flies is very true for civil aviation. Developments in Europe's civil aviation market place are following each other rapidly. Some of the carriers mentioned in the text of this study no longer exist, with their successors operating under different names, and

\footnotetext{
${ }^{5}$ Recent KLM-advertisements relate to the latter by mentioning a place abroad, then stating 'home at last' over a picture of a traveler being welcomed aboard a KLM plane.
} 
with a different scope and scale of operations. CrossAir and SN Brussels Airways, successors of SwissAir and Sabena respectively, can hardly be labeled as large carriers operating a huband-spoke network anymore. The recent merger of Air France and KLM may change the landscape of European civil aviation again, once they start coordinating their networks and flight schedules.

The literature has devoted some attention to the home carrier advantage under the label of 'airport dominance'. The first to tackle the problem of airport dominance empirically was Severin Borenstein in his 1989 paper. The variable reflecting hub dominance in Borenstein's paper is the average of a carrier's share of daily passengers originating at the two endpoints of the route, weighted by the proportion of passengers on the route who originate at each endpoint. Borenstein finds the effect of this variable on fare differences to be significantly positive, indicating that carriers with dominant positions at their hubs are able to charge higher prices. In his 1991 paper, Borenstein finds significant positive results, indicating that carriers exercise some market power over their hubs.

Berry (1990) estimates a structural model using airport presence as an explanatory variable in both cost and demand equations. Airport presence is defined as the number of top 50 cities served by an airline out of a given city. Berry finds that airport presence has a positive effect on demand and at the same time lowers costs. Though Berry interprets airport presence as product differentiation, which is different from Borenstein's market power approach of hub dominance, their results point into the same direction.

Evans and Kessides (1993) test whether airport and route market shares have a significant effect on fares. They find that airport dominance confers substantial pricing power upon the carrier, and that the isolated impact of route dominance on fares is insignificant. Evans and Kessides explain this difference by stating that, contrary to airports, routes are contestable since planes can easily be switched between routes, whereas airport facilities and FFPs can not.

Berry, Carnall and Spiller (1996) extend Berry's earlier work on the influence of airport presence on costs and demand. They find that airport presence has a positive effect on demand and a negative effect on costs. The cost-reducing effect of airport presence can be interpreted as the returns stemming from the economic rationale of the hub-and-spoke system. The effects are labeled 'hub premium', leaving aside whether it stems from product differentiation, market power or both.

The cost aspect is also present in Brueckner, Dyer and Spiller (1992) and in Brueckner and Spiller (1994), who focus on economies of density as an explanation for fares. Brueckner, Dyer and Spiller (1992) find that hub-originating and hub-terminating passengers pay higher fares, but cost advantages due to economies of density are passed on to passengers, thus reducing fares.

Goetz and Sutton (1997, p. 258) also find some indications of market power on concentrated hub markets. They find that '...passengers flying from small-city airports to 
major airports paid 34 percent more if the major airport was concentrated and 42 percent more if both the small-city and the major airport were concentrated.'

Marín (1995) was the first to address the issue in a European context, by estimating both a market share and a price equation, in a regulated and a deregulated segment. ${ }^{6}$ Marín finds that the effect of airport presence is not significant in a regulated environment and significantly negative in a deregulated environment. This implies that, contrary to the U.S. situation, European carriers in a deregulated environment tend to exploit the cost reducing effect of airport presence in order to compete in prices. Marín explains the difference between his European results and earlier U.S. estimates by signaling significant differences in the causes of market power. In Europe at that time, computer reservation systems were owned by multiple European carriers and FFPs hardly existed in Europe. Furthermore, Marín uses intraEuropean city pairs in his analyses. For these types of routes the hub and spoke system had not yet gained as much ground yet as it had in the U.S. aviation industry. Because of these differences, several causes of hub dominance had less impact than in the U.S., which may explain the absence of hub dominance in Marín's results.

\section{Empirical Indications for Home Carrier Advantages}

\subsection{Theoretical framework}

We use a simple hub-and-spoke network, as depicted in the right hand side of Figure 1. Airport $\mathrm{A}$ is an origin close to hub $\mathrm{H}$ and $\mathrm{Z}$ is defined as distant destination. This combination represents the common practice of Europe originating flights to other continents. We base our analysis on the assumption that fares depend on distance traveled, because costs are likely to be distance related- though not exclusively -, and fares are at least partly related to costs. Hansen (1990) and Windle and Dresner (1999) are examples of empirical studies on the relationship between fare and distance. Brander and Zhang (1993) find that costs per passenger are increasing but concave in distance. We capture this by using a logarithmic relationship between distance and fares. We define the fare from hub $\mathrm{H}$ to destination $\mathrm{Z}$ as:

$\log$ fare $_{H Z}=\alpha_{H Z}+\beta_{H Z} \log$ dist $_{H Z}+\chi C+\varphi_{H} H+\varphi_{Z} Z+h d p$

where dist $_{H Z}$ is the distance from airport $\mathrm{H}$ to airport $\mathrm{Z}, C$ is a vector of unobservable company-specific factors, $H$ and $Z$ are airport dummies ${ }^{7}$ and $\alpha_{H Z}, \beta_{H Z}, \varphi_{H}, \varphi_{Z}$ and $\chi$ are corresponding parameters. The variable $h d p$ represents the hub departure premium, an extra markup that the home carrier is confident enough to place on hub originating fares. This

\footnotetext{
${ }^{6}$ Marín uses a similar interpretation of airport presence as Berry (1990). His definition is also much alike, though fit to the European situation.
} 
premium may be caused by market power, as Borenstein (1989) suggests, or may be a form of product differentiation or both. The latter explanation, suggested by Berry (1990), implies that the carrier anticipates a higher willingness to pay for direct flights.

We should keep in mind that the premium as it is defined above, is a relative measure. Consider a situation where we, as we will do later in the paper, analyze fares of eight different companies. If we use the maximum number of seven company specific hdp's in our specification, the choice of the 'numéraire' would determine the sign of the hdp's. The 'numéraire' company is the one with the weakest airport dominance, which doesn't necessarily mean it has no dominance at all. This implies that the hub premiums estimated from the model measure the hub premium of a carrier on top of the lowest premium in the sample. Similar to equation (1), we define the fare of a flight from origin A via hub $\mathrm{H}$ to destination $\mathrm{Z}$ as:

$\log$ fare $_{A H Z}=\alpha_{A H Z}+\beta_{A H Z} \log$ dist $_{A H Z}+\chi C+\varphi_{A} A+2 \varphi_{H} H+\varphi_{Z} Z$

Note that we entered the dummy for the hub airport twice, since a return flight lands and takes off at the hub twice. Next, we use the distinction between close and distant spokes for scaling purposes, by defining relative fare, Rfare as $\frac{\text { fare }_{A H Z}}{\text { fare }_{H Z}}$. We may now write the equation for $\log$ Rfare as:

$\log$ Rfare $=\alpha+\beta_{A H Z} \log$ Rdist $+\varphi_{A} A+\varphi_{H} H+\left(\beta_{A H Z}-\beta_{H Z}\right) \log$ dist $_{H Z}-h d p$

where $\alpha=\alpha_{A H Z}-\alpha_{H Z}$, Rdist $=d i s t_{A H Z} / d i s t_{H Z}$ and parameter $\beta$ represents the fare elasticity of a small increase in distance, which should be comparable to the cost elasticity of a small increase in distance.

In aviation, costs are positively related to distance, but less than proportionally, so we expect $\beta$ to be between 0 and 1. Brueckner and Spiller (1994) point out that hub and spoke operations induce economies of density, which would imply that the sign of $\beta_{A H Z}-\beta_{H Z}$ should be negative.

Route competition, measured by the Herfindahl-Hirschman index (HHI) may also influence fares. ${ }^{8}$ Consistency in scaling would require the use of HHIs for both routes A-H-Z and H-Z. No major carriers share hubs in Europe however, so that any route A-H-Z is almost certainly only operated by H's home carrier. This problem may be mitigated by considering

\footnotetext{
${ }^{7}$ We have also tried to model airport specific factors by entering the country's income per capita. This implicitly denotes price discrimination, but it did not yield statistically significant results.

${ }^{8}$ Comparing direct and one-stop flights creates the need to correct for the inconvenience of the latter. We use the result found by Lijesen et al. (2004), giving a higher (1.63) weight to direct flights than to indirect ones.
} 
competition on city pair level rather than the level of individual itineraries. ${ }^{9}$ On city pair A-Z, itinerary $\mathrm{A}-\mathrm{H}-\mathrm{Z}$ is considered a close substitute to the direct flight. We use this notion to compute the HHI for city pairs A-Z as well as for city pair H-Z. Next we add the HHI's to equation (3):

$\log$ Rfare $=\alpha+\beta_{A H Z} \log$ Rdist $+\varphi_{A} A+\varphi_{H} H+\left(\beta_{A H Z}-\beta_{H Z}\right) \log$ dist $_{H Z}-h d p$

$+\phi_{H Z} H H I_{H Z}+\phi_{A Z} H H I_{A Z}$

\subsection{Data and empirical results}

We retrieved fare and frequency data from the internet. ${ }^{10} \mathrm{We}$ collected fare data for unrestricted economy class, which more or less means that we focus on the lower part of the market for business travelers. ${ }^{11}$ Our data on fares, travel times and distance relate to February 2000 , and are retrieved from the internet page of Travelocity, using a strict set of rules to ensure comparability of fares.

We built our database around the five largest European carriers and their intercontinental hubs: London Heathrow, Paris Charles de Gaule, Frankfurt, Amsterdam and Milan Malpensa. We selected ten European origins, among which these five main airports. The other European origins have different characteristics. Three of them (Zürich, Brussels and Athens) are also intercontinental hubs, be it hubs of medium sized international carriers. Another origin (Prague) is the hub of a carrier that operates mainly on European routes. The final origin to be mentioned here (Venice) is an airport that is not used as a hub by any carrier, but it is served by the main European carriers.

For the purpose of our analysis, we need five important non-European airports with a substantial amount of destination traffic. For this reason, we chose New York as an important U.S. East Coast destination, rather than Chicago O'Hare, which is the intercontinental hub of American Airlines, making it an important transfer point, rather than an important destination. Worldwide, important destination airports are almost always some carrier's hub, however. For these reasons, picking destinations is always slightly arbitrary.

We summarize our data in Table 2. Note that the minimum of Rfare is quite a bit below unity, indicating the existence of lower fares for connecting flights. In our sample, Rfare is below unity for 47 observations, be it that 33 of them are less then four percent below unity. Nevertheless, this indicates the presence of a hub departure premium.

\footnotetext{
${ }^{9}$ Note that competition at the city-pair level also implies that a flight from London Heathrow to New York JFK competes with a flight from London Gatwick to Newark.

${ }^{10}$ Many of the studies from the US use publicly available data on sold tickets and actual travel behaviour. Such data are not available in Europe

${ }^{11}$ This is consistent with the findings of Berry, Carnal and Spiller (1996).
} 
Table 2: Descriptive statistics

\begin{tabular}{lrrrr}
\hline & Mean & Stand. Dev. & minimum & maximum \\
\hline Fare (US\$) & 3094.08 & 1092.67 & 1073.60 & 5367.90 \\
Distance (Miles) & 5388.22 & 1658.92 & 1609 & 8242 \\
Rfare & 1.141 & 0.278 & 0.479 & 3.023 \\
Rdist & 1.106 & 0.180 & 1.015 & 3.153 \\
\hline
\end{tabular}

Table 3 presents the results from the estimation. Apart from the coefficients of the Herfindahl index and the constants, all parameters are statistically significant. Only one of the airport dummies (Brussels originating flights) yielded a significant parameter, the other ones were omitted from the analysis. We found positive and significant hub premiums for Swissair, Air France and Lufthansa. ${ }^{12}$ The parameter for the Herfindahl indices are not significantly different from zero. The hypothesis that economies of density arise from the hub-and-spoke operations is confirmed by the negative sign of $\beta_{A H Z}-\beta_{H Z}$.

Table 3: Regression results for log Rfare (t-values between brackets)

\begin{tabular}{lrr}
\hline Constant & & Equation (4) \\
& & 0.68 \\
$\log$ Rdist & $\beta$ & $(2.2)$ \\
& & 0.48 \\
cost difference between legs & $\beta_{A H Z}-\beta_{H Z}$ & $(3.6)$ \\
& & -0.08 \\
hub dominance premium for Air France & $h d p_{A F}$ & $(-2.5)$ \\
& & 0.14 \\
hub dominance premium for Lufthansa & $h d p_{L H}$ & $(4.4)$ \\
& & 0.15 \\
hub dominance premium for Swissair & $h d p_{S R}$ & $(4.4)$ \\
& & 0.13 \\
Brussels originating dummy & & $(3.5)$ \\
& & -0.58 \\
log of HHI of city pair & $\phi_{A Z}$ & $(-7.8)$ \\
& & -0.06 \\
log of HHI of main leg & $\phi_{H Z}$ & $(-1.2)$ \\
& & -0.03 \\
Log likelihood & & $(-0.5)$ \\
adjusted R & & 83.3 \\
& & 0.44 \\
\hline
\end{tabular}

For Swissair, the hub premium is about 13 percent, for Air France it is slightly higher at 14 percent. Lufthansa (15 percent) has the highest premium in this sample. Similar results are found by Berry, Carnal and Spiller (1996), who compute a hub premium of $19 \%$ for type 2 passengers on large hubs, roughly the US equivalent of the fares studied here.

\footnotetext{
${ }^{12}$ As stated before, the company with the lowest hdp should be the 'numéraire'. In the specification used here, Sabena is the 'numéraire', with Alitalia, Olympic, KLM and British Airways not differing significantly. These dummies were therefore omitted from the analysis.
} 
Comparing these results with the market shares of Europe's main hubs in Table 1 gives some room for the hypothesis that hub premiums are related to market power at airports, since Air France and Lufthansa (for which we found relatively high hub premiums here) have higher airport market shares than the other carriers. This result is consistent with Dresner and Windle (1992), who find that premium yields are positively related to airport market shares, and it suggests that favorable product characteristics are not the only reasons why fares from hub-originating flights are higher.

\section{Conclusion and Discussion}

This paper addresses the issue of relative position of the home carriers in hub-and-spoke systems. Hub-and-spoke systems are used by airlines to concentrate large numbers of passengers at their hub, thus giving rise to the exploitation of economies of density. Economies of density may lower costs on densely traveled routes and enable economically viable operations on less densely traveled routes. The reverse side is probably that carriers enjoy market power at their home base, labeled the home carrier advantage.

The home carrier advantage follows from carriers' favorable positions at their home base. Exploiting economies of density, they offer a higher number of direct flights from their hub at a higher frequency. This results in a higher product quality, as travelers are known to prefer direct flights, shorter travel times and higher frequencies. Other possible advantages for the home carrier follow from nonlinearities in Frequent Flyer Programs, language advantages, national pride and economies of density in advertisement in the home country.

We have developed a framework to establish empirically whether European carriers have a home carrier advantage or not. We use a cost-base approach of pricing flight tickets, taking a hub premium into account. We correct for unknown carrier specific characteristics by scaling all parameters of the indirect flights to their counterparts of the main leg of that same flight. Assuming a loglinear relationship between costs and distance, we establish an empirical relationship between fares, distance, route competition and hub premiums.

Borenstein (1989, 1991), Berry (1990), Evans and Kessides (1993) and Berry, Carnal and Spiller (1996) found positive hub premiums in the U.S. We established empirically that at least some European carriers charge premiums for flights originating from their hubs as well. We would like to stress that our results are relative results. This implies that the hub premiums of Lufthansa, Swissair and Air France are significantly higher than those of the other companies in our sample. These other companies do not necessarily refrain from charging hub premiums: they may also charge premiums, but lower than the ones that Lufthansa, Swissair and Air France charge. Also note that hub premiums may be used to cross-subsidize feeder flights in order to make optimal use of economies of density. This implies that hub premiums do not per se raise average fares. 
One may wonder whether 'hub premiums' follow from market power or from product differentiation. Both are probably true. The approach in Berry (1990) clearly follows the latter interpretation, whereas Borenstein $(1989,1991)$ looks at the phenomenon from the point of view of market power. The approach adopted in this paper follows the premium approach, implying a market power interpretation, though not excluding the product differentiation aspect.

An analysis slightly different from the one in this paper (Lijesen et al., 2002a) shows that product differentiation affects relative fares, and it does so in two ways. First, travelers are willing to pay more for higher quality (i.e., direct flights). Second, product differentiation limits competition because imperfect substitutes do not compete perfectly. The latter finding is a standard result from product differentiation in oligopoly models. So, fare differences stem partly from differences in product characteristics and partly from rents following from those differences. Furthermore, our findings in this paper that relative fares deviate from relative costs and that these deviations differ significantly between carriers suggest the presence of market power.

The relevance for competition policy is clear. Competition between full-service airlines using hub-and-spoke systems is imperfect in the sense that travelers will have to choose between imperfect substitutes. The hub carrier advantage involves rents which are likely to be sought by airlines. If we include routes also served by low cost carriers the hub carrier advantage decreases, since its main elements, direct flights and high frequencies, are generally also offered by the low cost carrier. This implies that the presence of a low cost carrier may seriously limit the home carrier in extracting rents from its home carrier advantage. It is therefore interesting to figure out how the entry of a low cost carrier on a route would influence the hub-based carrier's pricing decisions on that route, as well as on itineraries involving that route (see for example Alderighi et al., 2004). In the summer of 2003 British Airways was chosen as the best low-cost carrier during the Guardian/Observer travel awards, indicating that conventional airlines have responded to the emergence of low-cost carriers by lowering fares. On the other hand Pels and Rietveld (2004) find that in terms of yield management strategies, network carriers (British Airways, Air France) hardly react to price changes of low-cost carriers (easyJet, Buzz) in the London-Paris market. We may thus conclude that low-cost carriers have the potential to limit a hub-and-spoke airline's opportunity the charge hub-premiums. But further research is needed in this field to better comprehend the effects of market entry of low cost carriers on hub and spoke operations and on fare structures.

The home carrier advantage provides a rent-seeking opportunity for hub-and-spoke airlines. Passengers flying directly to their destination pay a relatively high fare due to a lack of direct competition form similar carriers (unless they fly with a low-cost carrier operating in a different market segment). Competition may be low because the market is too 'thin' to support multiple carriers, or simply because the necessary airport capacity is lacking. The 
passenger flow in markets with a relatively high hub premium will be relatively low; the airline extracts all rents, while revenues for the airport are relatively low. However, the airline can support this system because of the indirect passengers it transports, which cause the average costs per passenger to be relatively low. The airport thus also benefits from this system. For the surrounding economy, however, the origin-destination passengers (both business travelers and tourists) will be more interesting. While the business travelers may have a relatively high willingness-to-pay, leisure travelers (tourists) are price-sensitive. When the hub-premium is too high, tourists will find another destination, unless the market is also served by other, possibly low-cost carriers. Low-cost carriers will enter a market when the number of (potential) passengers is high enough to guarantee reasonable returns, and when slots are available at relatively low cost.

The obvious policy implication is that problems associated with the home carrier advantage may thus be mitigated by ensuring the possibility of entry. Apart from that, the hub carrier advantage calls for caution when measuring concentration, e.g. when assessing the competitive effects of a merger. ${ }^{13}$

\section{References}

Ahn, S.C., D.H. Good, R.C. Sickles, 1999, The Relative Efficiency and Rate of Technology Adoption of Asian and North American Airline Firms, in: T.-T. Fu, C.J. Huang, C.A.K. Lovell (eds.) Economic Efficiency and Productivity Growth in the Asia-Pacific Region, Cheltenham, Edward Elgar, 67-91.

Alderighi, M. A. Cento, P. Nijkamp and P. Rietveld, 2004, The entry of low cost airlines: price competition in the European airline market, Tinbergen Institute, Amsterdam.

Baker, S.H. and J.B. Pratt, 1989, Experience as a Barrier to Contestability in Airline Markets, The Review of Economics and Statistics, 71(2), pp 352-6

Berechman, J. and O. Shy, 1989, The Structure of Airline Equilibrium Networks, Recent Advances in Spatial Equilibrium Modelling (J.C.J.M. van den Bergh, P. Nijkamp and P. Rietveld, eds.), Springer-Verlag, Berlin 1998, pp. 138-156

Berechman, J. and J. de Wit, 1996. An Analysis of the Effects of European Aviation Deregulation on an Airline's Network Structure and Choice of a Primary West European Hub Airport, Journal of Transport Economics and Policy, 29, pp. 251-74.

Berry, S., 1990, Airport presence as product differentiation, American Economic Review, papers and proceedings, 80, pp. 394-99.

Berry, S., M. Carnall and P.T. Spiller, 1996, Airline hubs: costs, markups and the implications of customer heterogeneity, NBER Working paper 5561.

\footnotetext{
${ }^{13}$ See Lijesen et al (2002b, 2004)
} 
Bhat, C.R., 1995, A heteroscedastic extreme value model of intercity travel mode choice, Transportation Research, Part B, 29(6), pp. 471-83.

Bhat, C.R. 1997, An endogenous segmentation mode choice model with and application to intercity travel, Transportation Science, 31(1), pp. 34-48

Bissessur, A. and F. Alamdari, 1998, factors affecting the operational success of strategic airline alliances, Transportation, 25, pp. 331-55.

Borenstein, S., 1989, Hubs and high fares: dominance and market power in the US airline industry, Rand Journal of Economics, 20, pp. 344-65.

Borenstein, S., 1991, The dominant firm advantage in multi-product industries: evidence from the U.S. airlines, Quarterly Journal of Economics, 106, pp. 1237-66.

Borenstein, S. and M.B. Zimmerman, 1988, Market incentives for safe commercial airline operation, American Economic Review, 78(5), pp. 913-35.

Botimer, T.C., 1996, Efficiency Considerations in Airline Pricing and Yield Management, Transportation Research Part A, 30, pp 307-17.

Brander, J.A. and Zhang, A., 1990, Market conduct in the airline industry: an empirical investigation. RAND Journal of Economics 21, 567-583.

Brander, J.A and Zhang, A., 1993, Dynamic oligopoly behaviour in the airline industry, International Journal of Industrial Organization 11, 407-35.

Brueckner, J.K., 2002, Airport Congestion When Carriers Have Market Power, American Economic Review, 92(5), pp. 1357-75.

Brueckner, J.K., N.J. Dyer and P.T. Spiller, 1992, Fare determination in Airline Hub-andSpoke Networks, The RAND Journal of Economics, 23(3), pp. 309-33,

Brueckner, J.K., and E. Pels, 2004, European Airline Mergers, Alliance Consolidation, and Consumer Welfare, CESifo Working paper no. 1154.

Brueckner, J.K. and P.T. Spiller, 1994, Economies of traffic density in the deregulated airline industry, Journal of Law and Economics, 37, pp. 379-415.

Brueckner, J. and Y. Zhang, 2001, A Model of Scheduling in Airline Networks, Journal of Transport Economics and Policy, 35, pp. 195-222

Button, K., 1996, Liberalising European Aviation, is there an empty core problem?, Journal of Transport Economics and Policy, 29, pp. 275-91

Dana, J.D., 1999, Using yield management to shift demand when the peak time is unknown, RAND Journal of Economics, 30(3), pp. 456-74.

Daniel J.I., and M. Pahwa, 2000, Comparison of Three Empirical Models of Airport Congestion Pricing, Journal of Urban Economics, 50(2), pp. 230-58. 
Doganis, R., 1991, Flying off course, the economics of international airlines, $2^{\text {nd }}$ edition, London, Routledge.

Doganis, R. 1996, The Airport Business, $2^{\text {nd }}$ edition, London, Routledge.

Doganis, R. 2001, The Airline Business in the $21^{\text {st }}$ Century, London, Brunner-Routledge.

Dresner, M. and R. Windle, 1992, Airport Dominance and Yields in the U.S. Airline Industry, Logistics and Transportation Review, 28(4), pp. 319-39.

Evans, W.N. and I.N. Kessides, 1993, Localized market power in the U.S. airline industry, Review of Economics and Statistics, 70(1), pp. 66-75.

Fridström. L. and H. Thune-Larsen, 1989, An econometric air travel demand model for the entire conventional domestic network: the case of Norway, Transportation Research Part B, 23(3), pp. 213-23.

Ghobrial, A., 1993, A model to estimate the demand between US and foreign gateways, International Journal of Transport Economics, 20(3), pp. 271-83.

Goetz, A.R. and C.J. Sutton, 1997, The geography of deregulation in the U.S. airline industry, Annals of the Association of American Geographers, 87(2), pp. 238-63.

Hanlon, P., 1999, Global Airlines, Oxford, Butterworth Heinemann, $2^{\text {nd }}$ edition

Hansen, M., 1990, Airline competition in a hub-dominated environment: an application of noncooperative game theory, Transportation Research Part B, 24, pp. 27-43.

Harvey, G., 1987, Airport choice in a multiple airport region, Transportation Research Part A, 21, pp. 439-49.

Kanafani, A., and A. Ghobrial, 1985, Airline hubbing - some implications for airport economics, Transportation Research Part A, 19, pp. 15-27.

Lijesen, M.G., P. Rietveld and P. Nijkamp, 2002a, How do carriers price connecting flights? Evidence from intercontinental flights from Europe, Transportation Research Part E, $38 \mathrm{pp}$. 239-52

Lijesen, M.G., P. Rietveld and P. Nijkamp, 2002b, Measuring competition in civil aviation, Journal of Air Transport Management, 8, pp. 189-97

Lijesen, M.G., P. Rietveld and P. Nijkamp, 2004, Adjusting the Herfindahl index for close substitues, an application to pricing in civil aviation, Transportation Research Part E 40(2), pp. 123-34.

Marín. P.L., 1995, Competition in European aviation: pricing policy and market structure, The Journal of Industrial Economics, 18(2), pp. 141-59 
Marín, P.L., 1998, Productivity differences in the airline industry: Partial deregulation versus short run protection, International Journal of Industrial Organization, 16, pp. 395-414.

McGill, J.I. and G.J. van Ryzin, 1999, Revenue Management: Research Overview and Prospects, Transportation Science, 33(2), pp. 233-56.

Morrison, S.A and C. Winston, The Economic Effects of Airline Deregulation, Brookings Institution, Washington D.C, 1995

Nijkamp, P. and K. Button, 2003, Recent Advances in air transport economics, in: Cederlund, K. and U. Silbersky (eds), New Trends in the European Air Traffic, Rapporter och Notiser 164, Lund University.

Oum, T.H. and W.G. Waters II, 1996, A survey of recent developments in transportation cost function research, Logistics and transportation review, 32(4), pp. 423-63.

Oum, T.H., and C.Yu, 1998, Winning Airlines, Productivity and Cost Competitiveness of the World's Major Airlines, Norwell MA, Kluwer.

Park, J.-H., 1997, The effects of airline alliances on markets and economic welfare, Transportation Research, part E, 33(3), pp 181-95.

Pels, E., P. Nijkamp and P. Rietveld, 1997, Substitution and Complementarity in Aviation, Transportation Research E, 33, pp. 275-286

Pels, E, P. Nijkamp and P. Rietveld, 2002, Airport and Airline competition for Passengers Departing from a large Metropolitan Area, Journal of Urban Economics, 48, pp. 29-45.

Pels, E. and E.T. Verhoef, 2004, The economics of airport congestion pricing, Journal of Urban Economics, 55, pp. 257-277

Proussaloglou, K. and F. Koppelman, 1995, Air carrier demand, an analysis of market share determinants, Transportation, 22, pp. 371-88.

Reece, W.S. and R.S. Sobel, 2000, Targeting Teaching: Diagrammatic Approach to CapacityConstrained Price Discrimination, Southern Economic Journal, 66(4), pp. 1001-08.

Rose, N.L., 1992, Fear of flying? Economic analyses of airline safety, Journal of economic perspectives, 6(2), pp. 75-94.

Schipper, Y., P. Rietveld and P. Nijkamp, 2003, Airline Deregulation and External Costs: A Welfare Analysis, Transportation Research B, 37(8), pp. 699-718.

Suzuki, Y., 2000, The relationship between on-time performance and airline market share: a new approach, Transportation Research, Part E, 36, pp. 139-54.

Swait, J. and A. Bernardino, 2000, Distinguishing taste variation from error structure in discrete choice data, Transportation Research Part B, 34, pp. 1-15. 
Toh, R.S. and M.Y. Hu, 1988, Frequent-Flier Programs: passenger attributes and attitudes, Transportation Journal, 28(2), pp. 11-22

Windle, R. and M. Dresner, 1999, Competitive responses to low cost carrier entry, Transportation Research Part E, 35 pp. 59-75.

Winston, C., 1993, Economic Deregulation: Days of Reckoning for Microeconomists, Journal of Economic Literature, 31(3), pp. 1263-89.

Wit, R.C.N., M.D. Davidson and J.M.W. Dings, 2003, Meeting External Costs in the Aviation Industry, CE Delft. 